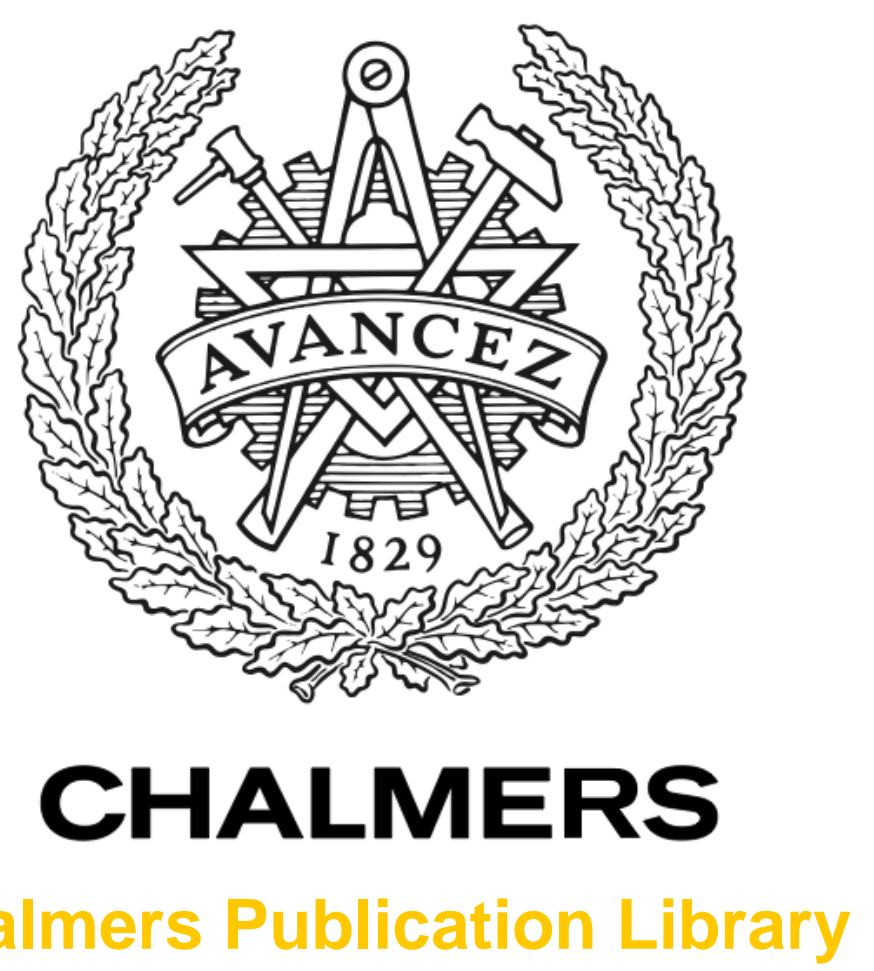

\title{
Role of Nitrogen Uptake During the Oxidation of 304L and 904L Austenitic Stainless Steels
}

This document has been downloaded from Chalmers Publication Library (CPL). It is the author's version of a work that was accepted for publication in:

Oxidation of Metals (ISSN: 0030-770X)

Citation for the published paper:

Cao, Y.; Norell, M. (2013) "Role of Nitrogen Uptake During the Oxidation of 304L and 904L Austenitic Stainless Steels". Oxidation of Metals, vol. 80(5-6), pp. 479-491.

http://dx.doi.org/10.1007/s11085-013-9391-1

Downloaded from: http://publications.lib.chalmers.se/publication/189301

Notice: Changes introduced as a result of publishing processes such as copy-editing and formatting may not be reflected in this document. For a definitive version of this work, please refer to the published source. Please note that access to the published version might require a subscription.

Chalmers Publication Library (CPL) offers the possibility of retrieving research publications produced at Chalmers University of Technology. It covers all types of publications: articles, dissertations, licentiate theses, masters theses, conference papers, reports etc. Since 2006 it is the official tool for Chalmers official publication statistics. To ensure that Chalmers research results are disseminated as widely as possible, an Open Access Policy has been adopted.

The CPL service is administrated and maintained by Chalmers Library. 


\title{
Role of Nitrogen Uptake in Oxidation of 304L and 904L Austenitic Stainless Steels
}

\author{
Yu Cao and Mats Norell \\ Materials and Manufacturing Technology, Chalmers University of Technology, 41296, Gothenburg, Sweden \\ yu.cao@chalmers.se; mats.norell@chalmers.se
}

\begin{abstract}
Nitrogen uptake affects corrosion of stainless steel in diesel exhaust systems where urea is injected to reduce $\mathrm{NO}_{\mathrm{x}}$. This was examined by exposing plasma nitrided $304 \mathrm{~L}$ and $904 \mathrm{~L}$ to humid air at $450-600^{\circ} \mathrm{C}$. The samples were characterized primarily by using XRD, AES and XPS. The as-nitrided samples had 10-20 atomic \% N in 3-40 $\mu \mathrm{m}$ layers dominated by expanded austenite supersaturated with $\mathrm{N}$, or S-phase. Nitrogen was detrimental with oxide thicknesses about 70-100 times thicker than on as received 304L and 2-5 times thicker on 904L. In the Sphase the $\mathrm{Cr}$ activity is reduced by short range ordering with $\mathrm{N}$, hampering formation of protective oxides. On 304L the fraction of thick oxides decreased significantly with increasing temperature, despite formation of $\mathrm{CrN}$, since formation of bcc promotes $\mathrm{Cr}$ diffusion. For 904L the S-phase is more stable and the corrosion less severe due to its alloying content. At $500^{\circ} \mathrm{C}$ formation of $\mathrm{CrN}$ enhanced the corrosion.
\end{abstract}

Keywords: stainless steel; nitriding; expanded austenite; oxidation.

\section{INTRODUCTION}

With the increasingly strict regulations on $\mathrm{NO}_{\mathrm{x}}$ emission in diesel exhaust gases of vehicles, selective catalytic reduction (SCR) using ammonia as reducing agent has been broadly applied. In this method, an aqueous solution of urea is often used as ammonia source to react with $\mathrm{NO}_{\mathrm{x}}$, forming $\mathrm{N}_{2}$ and $\mathrm{H}_{2} \mathrm{O}$. After component testing substantial $\mathrm{N}$ uptake has been found in exhaust systems at the urea injection where the corrosion was severe on 304L and limited on 904L [1]. The effect of the $\mathrm{N}$ uptake on the oxidation of stainless steel can thus be of great importance in an application running at varying temperatures up to $600^{\circ} \mathrm{C}$ where $\mathrm{N}$ might stay in solution or form other phases.

It is well known that $\mathrm{N}$ can be positive for wet corrosion resistance. Wet corrosion of nitrided stainless steel, including austenitic, ferritic and martensitic steels, has been investigated by many researchers [2-9]. Plasma nitriding may improve or deteriorate the corrosion resistance, depending on the nitriding temperature. Plasma nitriding at low temperatures $\left(\sim 400^{\circ} \mathrm{C}\right)$ produces a single phase which is known as S-phase or expanded austenite supersaturated with $\mathrm{N}$. The beneficial effect of nitrogen remains only when nitrogen is in solid solution, i.e., the S-phase is retained. The loss in corrosion resistance is owing to the formation of chromium nitrides. Once $\mathrm{CrN}$ is precipitated, depletion of chromium in the surrounding matrix will prevent the formation of protective oxide layer, impairing the corrosion resistance severely. The nitride formation temperature is material dependent, for instance it is higher for 316 than for 304 [6]. Concerning oxidation of stainless steel, nitriding has been found to improve the oxidation resistance of 304L stainless steel at $800^{\circ} \mathrm{C}$ where nitrides dissolve [10], but there are few studies in this field.

This laboratory study focuses on how simulated nitrogen uptake affects the structure and oxidation of 304L and $904 \mathrm{~L}$ in humid air at temperatures in the range $450-600^{\circ} \mathrm{C}$. Diesel exhaust gases typically contain $6 \% \mathrm{O}_{2}$ and $10 \%$ $\mathrm{H}_{2} \mathrm{O}$ so the atmosphere is reasonably related to the application, though the effect of water vapour is not the focus of this study. The nitrogen was induced in the steels by plasma nitriding, otherwise widely used to improve hardness and wear resistance. Samples were then annealed and oxidized to see how the distribution of $\mathrm{N}$ develops in the structure and how this affects the oxidation. It will be shown that $\mathrm{N}$ reduced the oxidation resistance for both alloys at all temperatures and that the oxidation rate correlates to the temperature and the $\mathrm{N}$ distribution but in different ways for the two alloys. 


\section{EXPERIMENTAL}

The materials studied were AISI 304L and 904L austenitic stainless steels, Tab. 1. The surface of each material was ground and polished down to $3 \mu \mathrm{m}$ diamond paste prior to plasma nitriding performed by Bodycote Värmebehandling $\mathrm{AB}$ at about $400^{\circ} \mathrm{C}$. Case layers with two different thicknesses and $\mathrm{N}$ contents (labelled $\mathrm{H}$ and $\mathrm{L}$ for High and Low) were obtained by modifying the $\mathrm{N}_{2}$ partial pressure and the treatment duration, as given in Tab.2. The thickness and composition of the layer have clearly been affected by other factors than gas composition and time, but that is out of the current scope. Aiming at the effect of $\mathrm{N}$ in the structure and not that of plasma nitriding, all samples were repolished to remove any possible reaction layer. This was checked by XPS on all samples and $\mathrm{XRD}$ was used to check that no structural changes occurred during polishing. The $\mathrm{N}$ surface concentration was measured by quantitative XPS analysis and the distribution by EDX. A well-defined nitriding layer was observed in all the cases. For both alloys the $\mathrm{N}$ concentration decreased slightly through the layer in condition $\mathrm{H}$, and to approximately half in condition $\mathrm{L}$. The concentration dropped distinctively below the layers.

After re-polishing nitrided and as-received coupons were oxidised in air with $10 \% \mathrm{H}_{2} \mathrm{O}$ vapour at $450-600^{\circ} \mathrm{C}$ for 24 and 168h with a gas flow rate of $6 \mathrm{l} / \mathrm{min}$ in a tube with a diameter of $75 \mathrm{~mm}$. Other coupons were annealed in Ar. The analyses showed that the same compounds formed in $\mathrm{Ar}$ and air. Since the structural changes could be studied on oxidised samples the detailed results obtained in Ar are not included.

TABLE 1. Chemical composition of AISI 304L and 904L stainless steel

\begin{tabular}{llllllllllll}
\hline Fe & C & Mn & Cr & Ni & Mo & Si & S & P & N & Cu & Ti \\
\hline Bal. & 0,019 & 1,63 & 18,25 & 8,05 & 0,43 & 0,28 & 0,001 & 0,028 & 0,072 & 0,33 & 0 \\
\hline Bal. & 0,011 & 1,62 & 20,3 & 24,26 & 4,37 & 0,33 & 0,001 & 0,023 & 0,054 & 1,41 & 0,007 \\
\hline
\end{tabular}

TABLE 2. Plasma nitriding conditions and nitrided layer characteristics for different samples.

\begin{tabular}{ccccc}
\hline Samples & $\begin{array}{c}\mathrm{N}_{2} \text { content } \\
\text { in gas }\end{array}$ & $\begin{array}{c}\text { Treatment } \\
\text { duration }(\mathrm{h})\end{array}$ & $\begin{array}{c}\text { Nitriding layer } \\
\text { thickness }(\mu \mathrm{m})\end{array}$ & $\begin{array}{c}\text { nitrogen surface } \\
\text { concentration (at\%) }\end{array}$ \\
\hline 304L-H & $25 \%$ & 99 & 40 & $18-20$ \\
\hline $304 \mathrm{~L}-\mathrm{L}$ & $6 \%$ & 24 & 7 & $18-20$ \\
\hline $904 \mathrm{~L}-\mathrm{H}$ & $25 \%$ & 99 & 20 & $14-15$ \\
\hline $904 \mathrm{~L}-\mathrm{L}$ & $6 \%$ & 24 & 3 & $9-10$ \\
\hline
\end{tabular}

Several characterization methods were used to investigate the phases formed, microstructure and oxidation behaviour, including optical microscopy, XRD, SEM, EDX, AES and XPS. The phases formed in the nitriding layer prior and after oxidation were identified by means of Bruker AXS D8 advance X-ray diffraction system in the range of $2 \theta=30-160^{\circ}$ using $\mathrm{CrK} \alpha$ radiation. Thin layers were studied at grazing angles $1-3^{\circ}$. The oxide thickness and element distribution in depth were determined using both XPS and AES by successive argon ion etchings and analyses with etch rates calibrated on $\mathrm{Ta}_{2} \mathrm{O}_{5}$ with known thickness. The XPS was a PHI5500 using AlKa X-ray source and the AES depth profiles were obtained by means of a ThermoScientific Microlab 350. Sensitivity factors from the instrument manufacturers were used in XPS and AES except for O in AES where the factor was adjusted to indicate concentrations similar to the XPS results. Optical microscopy and a LEO Gemini 1550 SEM in conjunction with Oxford Inca EDX system were utilized to examine cross sections using $20 \mathrm{kV}$ acceleration voltage.

\section{RESULTS}

The first nitriding condition, $\mathrm{H}$, resulted in $\mathrm{N}$ concentrations almost twice as high as those on corroded components in 904L [1]. Moreover, for 904L a multitude of cracks formed both through the layer thickness and in parallel with the surface. These cracks clearly indicated high stresses as a result of the nitridation. Since both the cracks and the $\mathrm{N}$ concentration were not relevant for the application and could affect the oxidation behaviour, the second nitridation was done, condition L. Though the surface concentrations were not much lower there were few cracks and indications of lower stresses in the thinner layers. Samples from condition H have been analysed in some conditions. There are some differences between the structures from the two conditions but their oxidation behaviours were rather similar. Still, most of the exposures, the analyses and the discussion relate to condition $\mathrm{L}$.

Table 3 gives an overview of the oxide thickness, as calibrated on $\mathrm{Ta}_{2} \mathrm{O}_{5}$, after 24h according to AES or XPS profiles. Where two figures are given there were areas with thin and thick oxides. The thickness measurements on 
thin oxides are reproducible within some $5 \%$. The thickness of the thick oxides on 304L varies significantly over the surface as can be seen in Fig. 2. Therefore values given for these thicknesses are characteristic examples based on multiple measurements. The coverage of thick oxides decreased with increasing temperature. Since the sample had to be tilted and the beam defocused to counteract charging, the thickness of the comparatively small areas of thin oxide could not be determined at the lower temperatures. Compared to the as- received alloys the oxides on both nitrided conditions were roughly 70-100 times thicker on 304L and 2-5 times thicker even on the highly alloyed 904L. The oxide peak height in XRD correlated with the oxide thickness. Therefore these heights will be taken as an indication of the oxidation on 168h samples where no profiles have been recorded. From the XRD pattern it could also be seen that the as received alloys remained austenitic at all temperatures, with only minor bcc peaks for 304L. Most of the results below focus on how the structure and oxide changes with temperature for nitrided samples.

TABLE 3. Oxide thickness (nm) for materials oxidized at different temperatures for $24 \mathrm{~h}$ in $10 \% \mathrm{H}_{2} \mathrm{O}$.

\begin{tabular}{|c|c|c|c|c|c|c|c|c|c|c|c|c|c|c|}
\hline Alloy & \multicolumn{7}{|c|}{$304 \mathrm{~L}$} & \multicolumn{7}{|c|}{$904 \mathrm{~L}$} \\
\hline Nitriding & none & none & $\mathrm{H}$ & $\mathrm{L}$ & $\mathrm{L}$ & $\mathrm{L}$ & $\mathrm{L}$ & none & none & $\mathrm{H}$ & $\mathrm{L}$ & $\mathrm{L}$ & $\mathrm{L}$ & $\mathrm{L}$ \\
\hline Temp. $\left({ }^{\circ} \mathrm{C}\right)$ & 450 & 600 & 450 & 450 & 500 & 550 & 600 & 450 & 600 & 450 & 450 & 500 & 550 & 600 \\
\hline XPS & 28 & 37 & 2200 & & & & & 32 & & 250 & & & & 110 \\
\hline AES & & & & 2500 & 4500 & $\begin{array}{l}470 / \\
4000\end{array}$ & $\begin{array}{l}560 / \\
2600\end{array}$ & & 50 & & 150 & 210 & 135 & \\
\hline
\end{tabular}
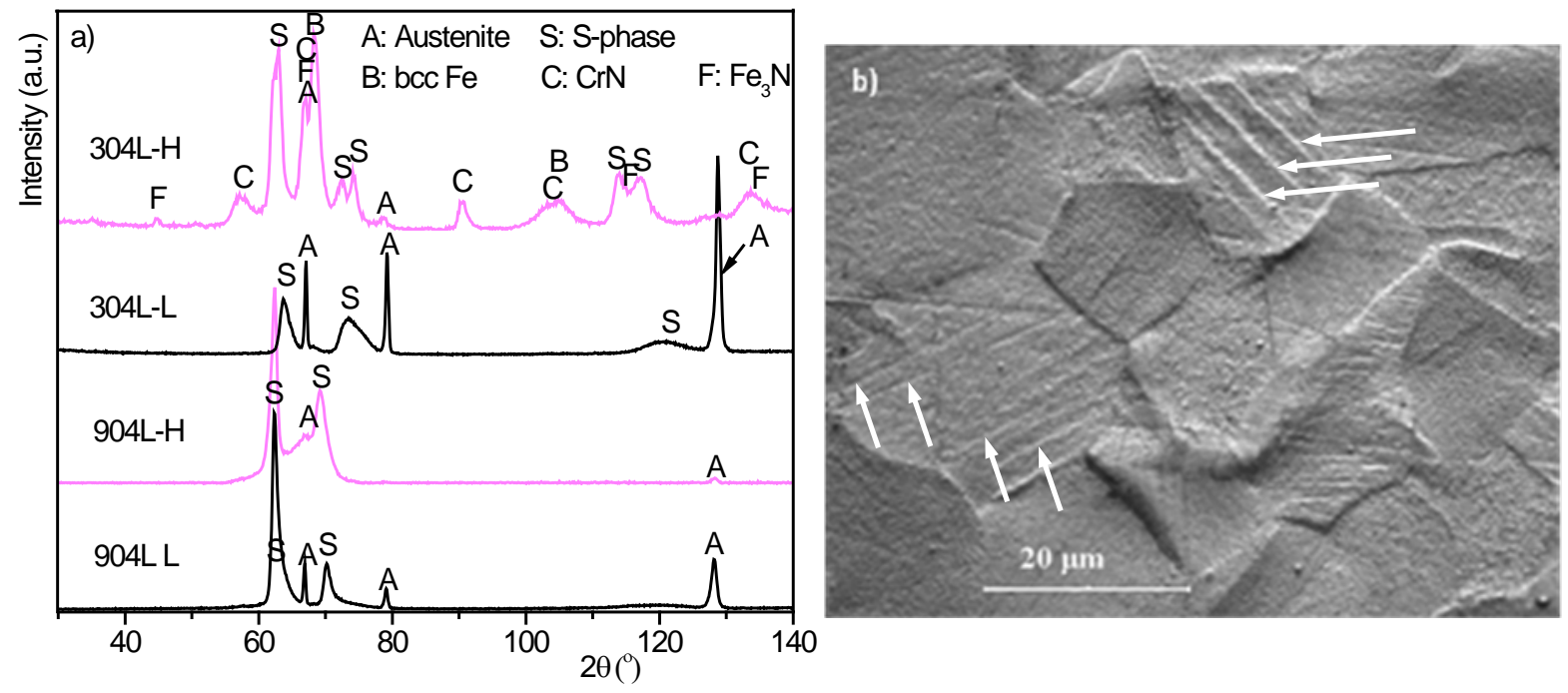

FIGURE 1. a) XRD pattern from as-nitrided materials; b) Optical microstructure of as-nitrided 304L-L with slip bands indicated by arrows.

\section{As Nitrided Material}

Figure 1a gives the XRD pattern from the nitrided 304L and 904L. After nitriding, the layers on 904L (H and L) consisted of austenite and S-phase which is generally considered as a metastable expanded austenite supersaturated with $\mathrm{N}$ atoms. Compared to 904L-H, the S-phase peaks in 904L-L shift slightly towards higher angles, consistent with the lower layer thickness and $\mathrm{N}$ concentration. Moreover, the shoulder at the high angle side of the S-phase indicates the $\mathrm{N}$ concentration gradient, and possibly stress gradient, within the modified layer. In 304L-L, similarly, a single broad peak representing S-phase appears at the left of each austenite peak. However, the phase constituent in 304L-H was more complicated. The S-phase under this condition has double peaks which might be attributed to the tertragonal distortion [11] or dual layer structure with different magnetic properties [12]. The double peaks from S-phase at higher $2 \theta$ angle are more split. At the same time, bcc iron, $\mathrm{CrN}$ and possibly some $\mathrm{Fe}_{3} \mathrm{~N}$ formed in 304L$\mathrm{H}$, indicating S-phase was less stable in 304L than in 904L. It is generally accepted that nitride is not able to form in plasma nitriding at temperature as low as $400^{\circ} \mathrm{C}$. However, it might not be the case when the time for nitriding is long enough. Moreover, the well-defined interface, and the sudden drop of $\mathrm{N}$ content there, imply that the S-phase is quite different from the austenite. 
Figure $1 \mathrm{~b}$ shows the top surface after plasma nitriding for 304L-L. The grain structure was revealed by the etching effect of the plasma during nitriding. Parallel slip bands, as indicated by arrows, can be observed in some grains with different orientations from grain to grain. As a sign of plastic deformation, these slip bands are attributed to the stresses induced by the formation of the S-phase as the austenite lattice expands by interstitially dissolved $\mathrm{N}$.

\section{Oxidation of nitrided 304L}

Figure 2 shows the oxides formed on $304 \mathrm{~L}-\mathrm{L}$ after $24 \mathrm{~h}$ at $450-600^{\circ} \mathrm{C}$. At all temperatures areas of thin and thick oxides formed and the area fraction of thick oxides somewhat unexpectedly decreased with increasing temperature.
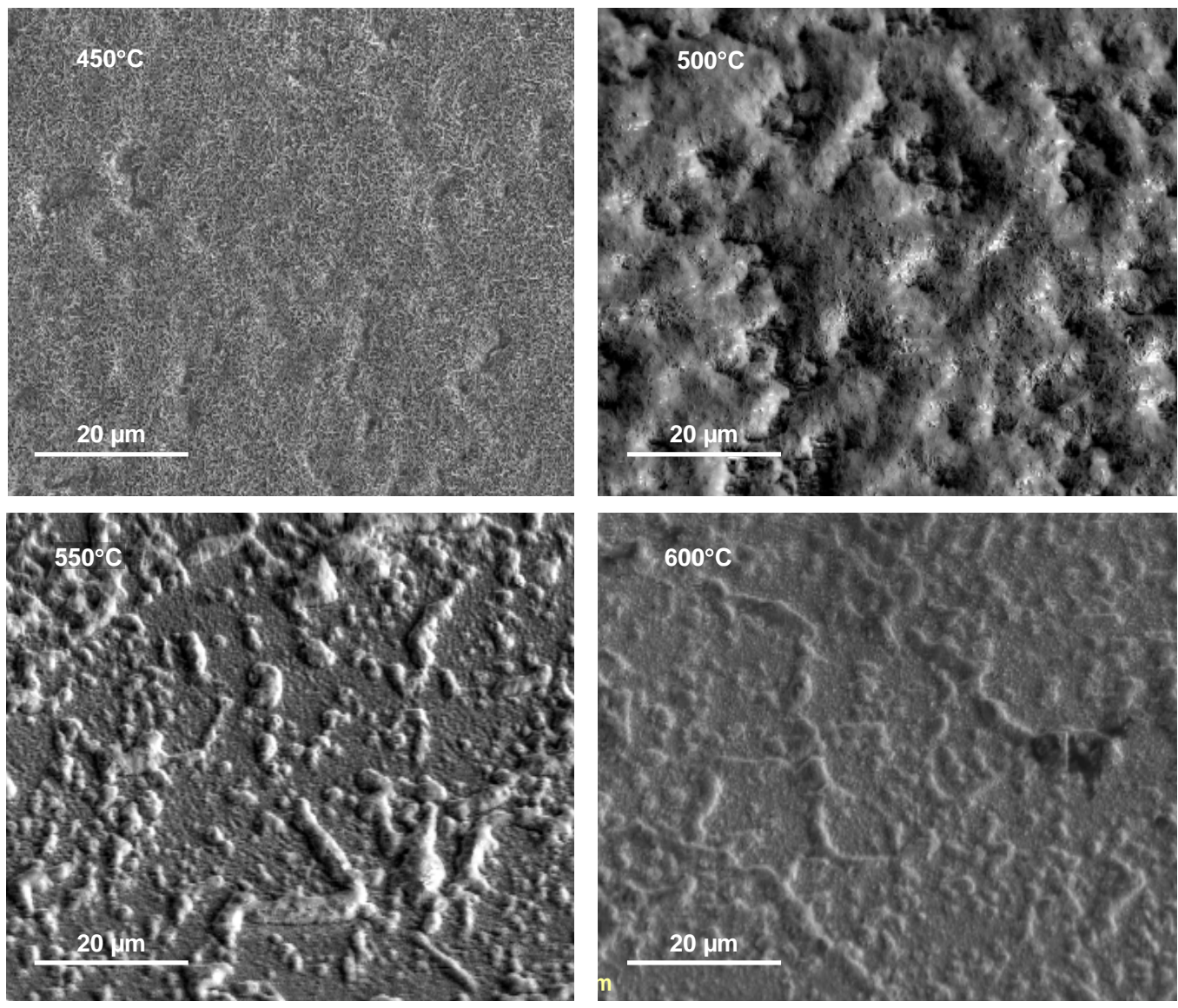

FIGURE 2. Surface morphology of 304L-L after oxidation for $24 \mathrm{~h}$ at the temperatures indicated in the images.

The AES profiles in Fig. 3 illustrate examples of oxide structures formed after $24 \mathrm{~h}$ at $600^{\circ} \mathrm{C}$. As-received $304 \mathrm{~L}$ had an outer Fe-oxide and an inner Cr-rich oxide with a total oxide thickness of about $37 \mathrm{~nm}$. The thinner oxide (Fig 3b) on 304L-L was mostly an Fe-oxide enriched in $\mathrm{Mn}$ in its outer part but no distinct Cr-enrichment at the metal-oxide interface. The thicker oxide (Fig. 3c) was a rather pure Fe-oxide in its outer part with an FrCr-oxide at the interface. The structures for the thin and thick oxides respectively were similar at all temperatures and the thicknesses did not vary much as seen in Tab. 3. The main difference between the temperatures was the coverage of thick oxides.

XRD results show that the oxides formed on 304L-H consisted of both hematite and spinel (possibly as magnetite) (Fig. 4). Since relatively thick oxides have formed only small peaks from metal could be detected by XRD after oxidation at $500^{\circ} \mathrm{C}$ for $168 \mathrm{~h}$. For 304L-L, less spinel and hematite was developed at temperatures higher than $500^{\circ} \mathrm{C}$, consistent with the lower surface fraction of thick oxide.

The decomposition of the S-phase during the oxidation at high temperatures was of great interest. Upon increasing temperature or prolonging time, the diffraction peaks of the S-phase were shifted to higher $2 \theta$ angles and merged gradually into the Austenite peak. It could only be partially resolved from the Austenite at higher temperature and longer time because there was less $\mathrm{N}$ in solution. The lattice parameter of the S-phase increases with increasing $\mathrm{N}$ concentration [13]. The observed peak shift indicated the removal of interstitial $\mathrm{N}$, accompanying 
the transformation from highly expanded structure to less expanded one and the observed precipitation of CrN. In 304L-H large amounts of bcc formed during nitridation. For 304L-L similar amounts formed in parallel with the decomposition of the S-phase. The bcc peak from the $450^{\circ} \mathrm{C}$ sample was clearly broadened, and to some extent that from $500^{\circ} \mathrm{C}$ as well, whereas both the bcc peak and the smaller one for fcc were narrow for the $550^{\circ} \mathrm{C}$ and $600^{\circ} \mathrm{C}$ samples. The broad diffraction peak from $\mathrm{CrN}$ at lower temperature was attributed to a fine grain size. TEM investigation of $304 \mathrm{~L}$ nitrided at $450^{\circ} \mathrm{C}$ for $5 \mathrm{~h}$ confirmed the formation of very fine precipitates in the range of a few nanometers [14]. The CrN peaks became narrower with increasing temperature, consistent with increasing grain size.

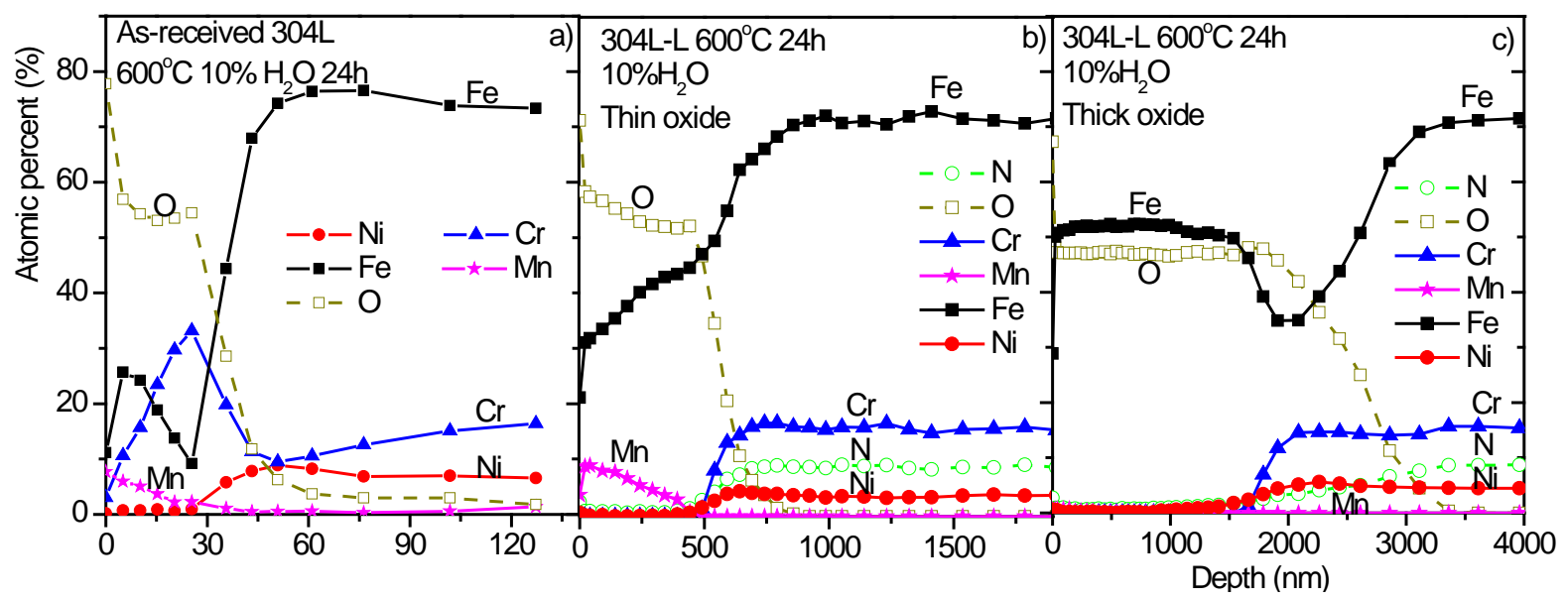

FIGURE 3. Depth profiles of 304L-L after oxidation for $24 \mathrm{~h}$ in humid air at $600^{\circ} \mathrm{C}$; a) as-received (XPS); b) 304L-L thin oxide (AES) and c) 304L-L thick oxide (AES).
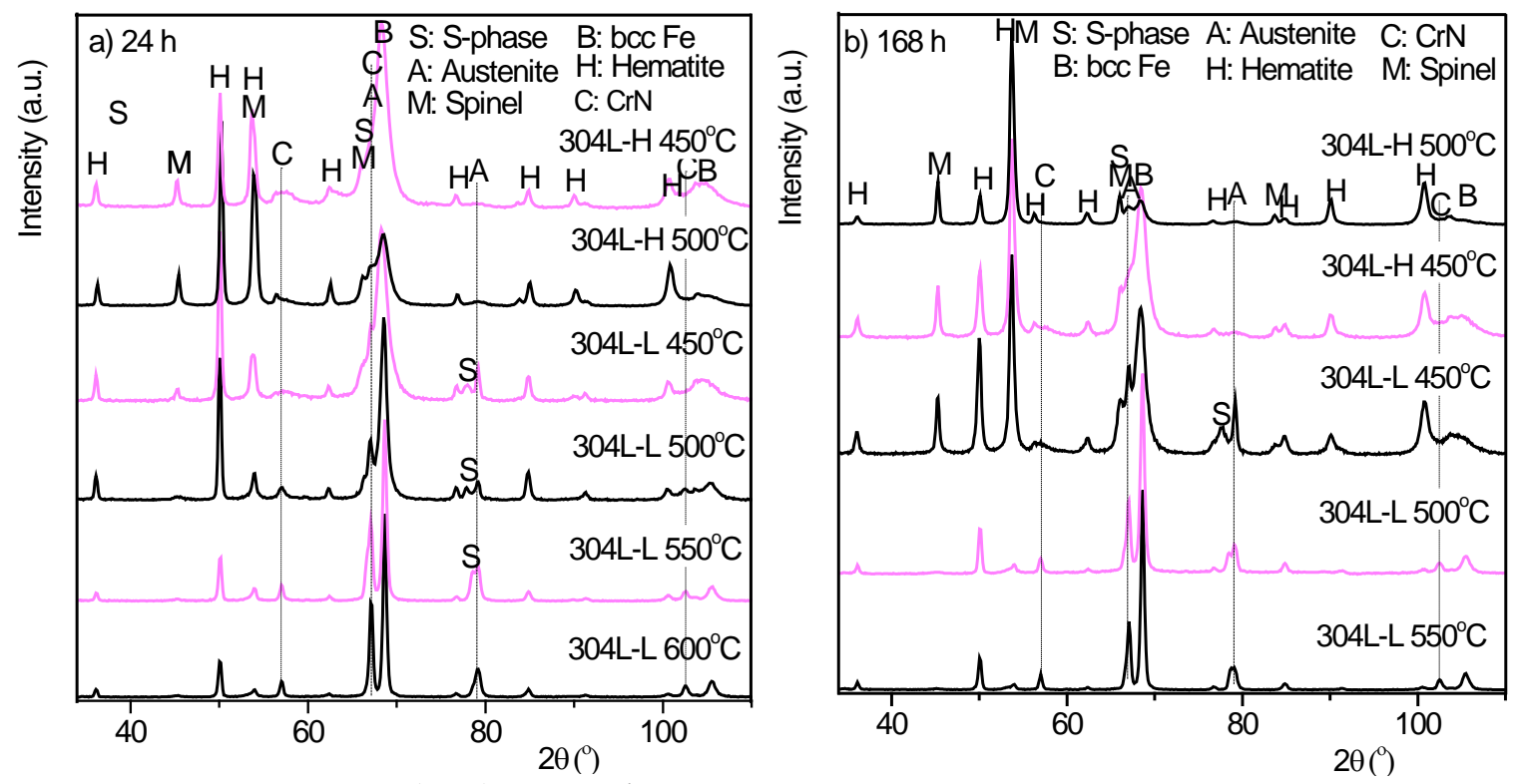

FIGURE 4. Bragg-Brentano ( $\theta-2 \theta)$ symmetric geometry X-ray diffraction pattern from 304L oxidized for a) 24h and b) 168h. The dashed and dotted lines represent the position of Austenite and CrN, respectively.

\subsection{Oxidation of nitrided 904L}

The oxides formed on nitrided 904L were thicker than on as received 904L, but significantly thinner than on nitrided 304L. Furthermore, SEM observations showed that the oxides were even and multiple AES profiles showed that they had uniform in thickness. As shown in Tab. 3 the thickest oxides formed at $500^{\circ} \mathrm{C}$. Figure 5 presents AES 
depth profiles of 904L-L after oxidation for $24 \mathrm{~h}$. At $450^{\circ} \mathrm{C}$ there was an outer $120 \mathrm{~nm}$ Fe-oxide and inner $\mathrm{FeCr}$ oxide, while there was no obvious $\mathrm{Cr}$-enrichment in the inner parts of the thicker oxide formed at $500^{\circ} \mathrm{C}$. Again, at the higher temperatures 550 and $600^{\circ} \mathrm{C}$, inner Cr-rich oxides were observed.

Since the oxides were thin, grazing angle incidence XRD was used to identify the oxidation products. The oxides on 904L-H were thicker than on 904L-L and consisted of both hematite and spinel phase, (Fig. 6). For 904L-L, no obvious spinel phase was observed and the oxide was considerably thinner than on 904L-H. The later was attributed to the lower amount of $\mathrm{N}$ in condition L. Consistent with the oxide thickness, the highest hematite intensity was obtained at $500^{\circ} \mathrm{C}$ for both long and short time exposure. Interestingly, this correlated with the amount of CrN which also had a maximum intensity at $500^{\circ} \mathrm{C}$ (see Fig. 6). Similar to 304L, the effect of exposure time on oxidation was not as important as temperature. The variation of the diffraction peaks from the S-phase with the temperature or time followed a similar trend as for $304 \mathrm{~L}$, while the S-phase gave stronger peaks in $904 \mathrm{~L}$ as evident at $450^{\circ} \mathrm{C}$ for both conditions $\mathrm{L}$ and $\mathrm{H}$. Furthermore, close examination of the XRD patterns show that in 904L-L the S-phase still remained at $600^{\circ} \mathrm{C}$. Altogether, this indicated again that the S-phase was more stable in 904L than in 304L.
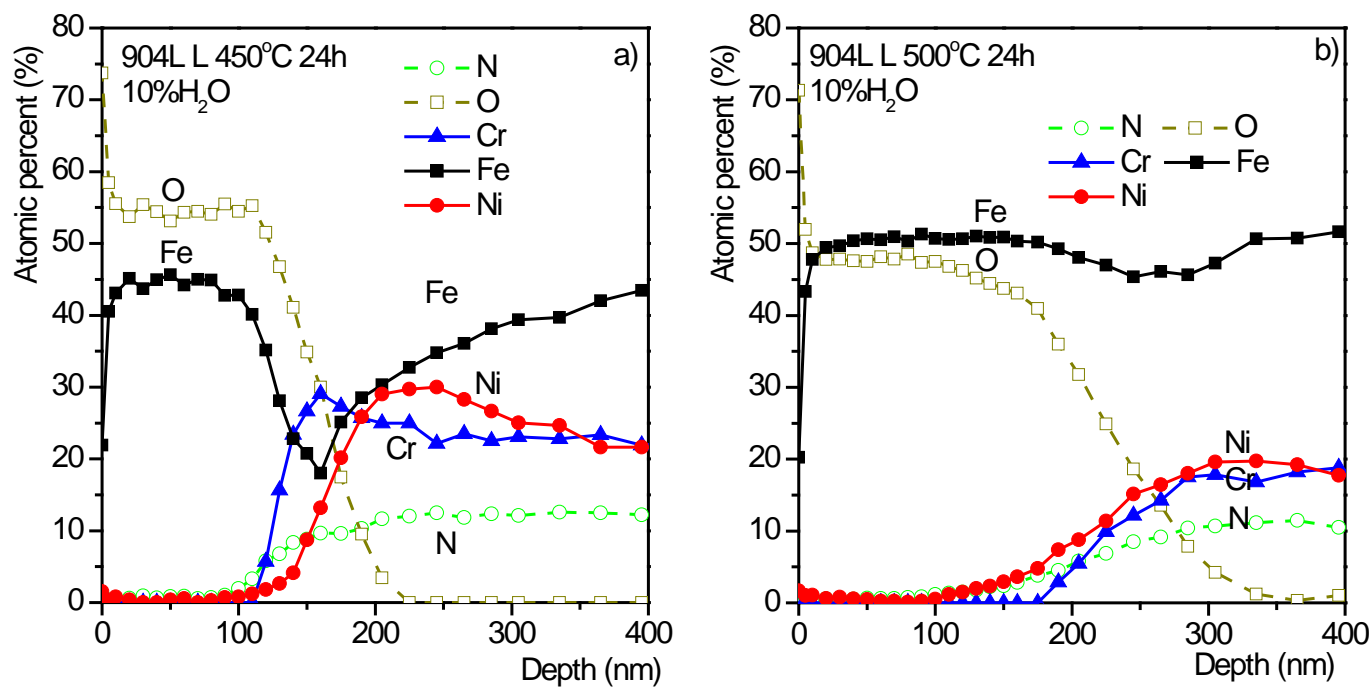

FIGURE 5. AES depth profiles of the oxidized 904L-L after oxidation at $450^{\circ} \mathrm{C}$ a) and $500^{\circ} \mathrm{C}$ b) for $24 \mathrm{~h}$.
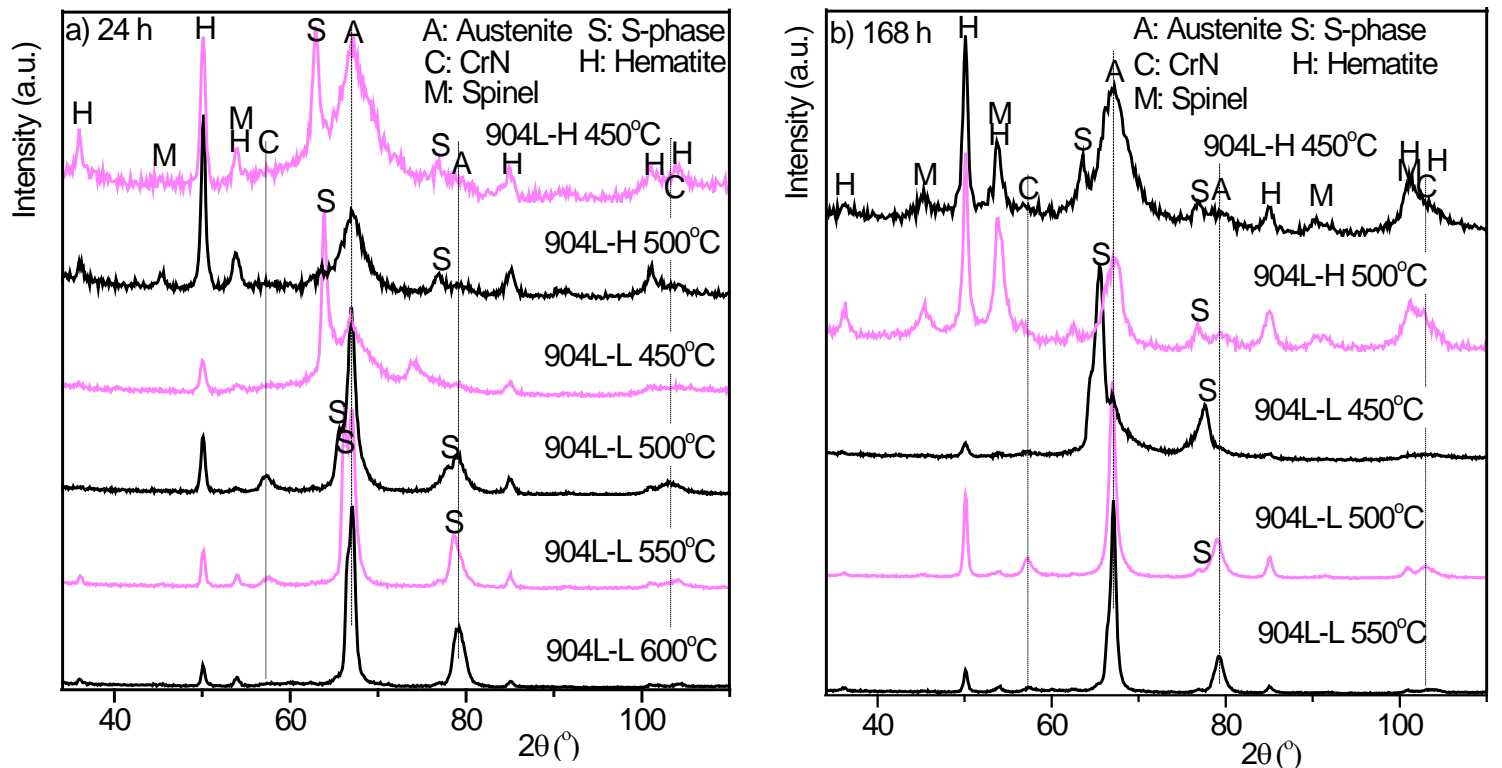

FIGURE 6. Grazing angle incidence ( $\left.3^{\circ}\right)$ X-ray diffraction pattern from 904L oxidized for a) $24 \mathrm{~h}$ and b) 168h. The dashed and dotted lines represent the position of Austenite and CrN, respectively. 


\section{DISCUSSION}

It has been found in this study that plasma nitriding at about $400^{\circ} \mathrm{C}$ deteriorates the oxidation resistance of the studied stainless steels in the temperature range $450-600^{\circ} \mathrm{C}$. The effect was very strong on $304 \mathrm{~L}$, but clear also for 904L. As expected, the oxidation products formed were mostly Fe- and FeCr-oxides. The outer part of the thin oxide on 304L is also enriched in $\mathrm{Mn}$ as reported previously for humid air [15]. The corrosion mechanisms are presumably the normal for the environment where evaporation of $\mathrm{Cr}$ containing species may contribute to the attack, at least for 304L [16]. The focus here will be on how $\mathrm{N}$ and the phases formed affect the availability of $\mathrm{Cr}$ to form protective oxides. Nitrogen did accelerate the corrosion in all conditions but to varying degrees, and from this we can get a better understanding of the mechanisms.

In all samples $\mathrm{N}$ was present in the S-phase or in CrN. Nitride formed already in the as nitrided 304L-H, but otherwise $\mathrm{N}$ was in the S-phase after nitridation. In the classic sensitisation, $\mathrm{Cr}$ is in solution until precipitates such as nitrides form and the wet corrosion resistance is reduced. Here, the corrosion properties were poorer than in as received material also when $\mathrm{N}$ was mostly in the S-phase as at $450^{\circ} \mathrm{C}$ for $304 \mathrm{~L}$ and at $450^{\circ} \mathrm{C}$ and $600^{\circ} \mathrm{C}$ for $904 \mathrm{~L}$. Actually, pronounced short-range ordering of $\mathrm{Cr}$ and $\mathrm{N}$ has been found in S-phase supersaturated with $\mathrm{N}$, by extended X-ray absorption fine structure investigation [17]. Nitrogen tends to reside in the immediate vicinity of $\mathrm{Cr}$ atoms and the affinity between these two atoms is high. Cr acts as nitrogen trap [18]. Here, it is concluded that such ordering reduced the activity of $\mathrm{Cr}$ and hindered the formation of a protective $\mathrm{Cr}$ rich oxide even when no $\mathrm{CrN}$ was detected. Consequently, thicker oxides formed. For the more highly alloyed 904L it is reasonable to believe that more $\mathrm{Cr}$ remained available, there is less Fe than in 304L, and the effect was not as strong.

The same short range ordering that hinders the formation of protective $\mathrm{Cr}$ containing oxides may facilitate the nucleation of $\mathrm{CrN}$. In 304L nitrides form already in the as nitrided $304 \mathrm{~L}-\mathrm{H}$ and at $450^{\circ} \mathrm{C}$ for $304 \mathrm{~L}-\mathrm{L}$. With increasing temperature the $\mathrm{CrN}$ peaks got clearer. The formation of $\mathrm{CrN}$ should also lower the $\mathrm{Cr}$ activity. Nevertheless, the area fraction of thick oxides decreases considerably with increasing temperature, contrary to classic sensitisation. Though it was not possible to examine weight gain, the appearance and composition of the thin and thick oxides clearly indicate breakaway corrosion that has developed further after $24 \mathrm{~h}$ at 450 and $500^{\circ} \mathrm{C}$ than at the higher temperatures. Reasonably, at the lower temperatures the alloy could not maintain a protective $\mathrm{Cr}$ rich oxide as long as at higher temperatures. On the other hand, in parallel with the formation of nitrides substantial amounts of bcc formed to the extent that the bcc peak was stronger than that of austenite for all oxidised samples of 304L. At the higher temperatures the bcc peaks in XRD were distinct. In 304L-H bcc formed already during nitriding that was done at about $400^{\circ} \mathrm{C}$. This bcc was presumably formed as martensite due to the considerable residual stresses that can occur in S-phase, as observed by Xu et al [19]. For 304L-L bcc formed during oxidation. The narrow peaks at 550 and $600^{\circ} \mathrm{C}$ could be consistent with a phase transformation

$$
\mathrm{S} \rightarrow \mathrm{bcc}+\mathrm{fcc}+\mathrm{CrN}
$$

This confirms that the $\mathrm{S}$ phase is less stable than austenite since, in comparison, the minor amount of bcc in as received 304L did not increase during oxidation. Several factors could contribute to the broad peak for bcc at $450^{\circ} \mathrm{C}$. Gradients in the high residual stresses or in the $\mathrm{N}$ content through the layer could cause a variation in the lattice parameter. There is also a possibility that the bcc is the result of a martensite transformation [19]. Here, the focus is on the consequences of the formation of bcc for the oxidation which is that it will enhance the diffusion of the $\mathrm{Cr}$ that remains in solution, despite the formation of nitrides, and thus promote the formation of Cr-rich oxides. The formation of bcc and the high diffusivity in it is suggested to contribute to the improved corrosion resistance at higher temperature. It is worth to point out that the effect of $\mathrm{N}$ reported in this study may well be different from that for lower $\mathrm{N}$ concentrations where lower residual stresses develop and the formation of bcc structure might not be triggered.

The effect of plasma nitriding on 904L was clear, but less serious than for 304L, owing to the composition and microstructure. The S-phase is more stable in 904L than in 304, as shown by Figs. 2 and 6. Compared to 304L, 904L contain 3 times more Ni and 10 times more Mo. Apart from Ni being an austenite stabilizer, large Mo atoms can widen the octahedral sites in the fcc structure [20], thus stabilizing the S-phase and depressing the precipitation of chromium nitride. The Ni-content and the stability of the S-phase could also explain why no bcc-iron was observed in 904L even though the abundant crack formation especially in 904L-H indicate that the residual stresses were possibly higher than in 304L. Despite the fact that no bcc could enhance the diffusion, slip bands similar to those in Fig. 1b indicate that the residual stresses has been partly relaxed by a deformation that induces fast diffusion paths such as dislocations. This should somewhat promote the formation of protective oxides. 
There was a certain variation in oxide thickness with temperature for 904L so that a somewhat thicker oxide with no obvious Cr-enrichment in its inner part formed at $500^{\circ} \mathrm{C}$. Still, the oxide was smooth and appeared to be rather protective. From the diffraction patterns it can also be seen that the strongest $\mathrm{CrN}$ peak occurred at the same temperature, it was less intensive at $550^{\circ} \mathrm{C}$ and weak at $600^{\circ} \mathrm{C}$. It has been reported that the fraction of $\mathrm{CrN}$ phase in 316 steel decrease with nitriding temperature in the range of $400-550^{\circ} \mathrm{C}$ [21]. Here, it is likely that the precipitation of $\mathrm{CrN}$ at $500^{\circ} \mathrm{C}$ removed $\mathrm{Cr}$ from solid solution and adversely affected the oxidation performance at this temperature.

This study was initiated to examine the role of the substantial uptake of $\mathrm{N}$ in connection with corrosion of the alloys at the urea injection in diesel exhaust systems [1]. In the application the corrosion of 304L was severe and that of 904L limited, but noticeable. From this laboratory study it is clear that $\mathrm{N}$ can accelerate the corrosion of 304L in the temperature range $450-600^{\circ} \mathrm{C}$ substantially. Furthermore, the corrosion resistance of the highly alloyed 904L is also hampered to some extent.

\section{CONCLUSIONS}

The surface layers on plasma nitrided alloys 304L and 904L were dominated by expanded austenite supersaturated with $\mathrm{N}$, or S-phase.

The oxides formed at $450-600^{\circ} \mathrm{C}$ on nitrided samples of 304L were about $70-100$ times thicker than on as received material, and those on 904L were about 2-5 times thicker. Thus, $\mathrm{N}$ was detrimental for the oxidation properties.

It is proposed that short range ordering between $\mathrm{Cr}$ and $\mathrm{N}$ in the S-phase reduces the activity of $\mathrm{Cr}$ and hinder the formation of a protective $\mathrm{Cr}$ rich oxide.

For 304L the surface fraction of thick oxides decreases with increasing temperatures, consistent with an improved corrosion resistance. In parallel $\mathrm{CrN}$ and bcc are formed. Though the nitrides may decrease the activity of $\mathrm{Cr}$, the high diffusivity in the bcc is suggested to contribute to the improved corrosion resistance at higher temperature.

For $904 \mathrm{~L}$ the S-phase is more stable and the corrosion less severe due to the alloying content. At $500^{\circ} \mathrm{C}$ formation of $\mathrm{CrN}$ is proposed to enhance the oxidation as compared to higher and lower temperatures.

\section{ACKNOWLEDGMENTS}

This work was performed within the High Temperature Corrosion Centre and was financed by the National Swedish Energy Administration. The project was performed in co-operation with Volvo Powertrain and Outokumpu Stainless. Prof. L-G Johansson is acknowledged for valuable discussions.

\section{REFERENCES}

1. J. Nockert. and M. Norell. Materials and Corrosion 62 (2011) DOI: 10.1002/maco.201005983

2. H. Baba, T. Kodama and Y. Katada, Corrosion Science 44, 2393 (2002).

3. C.X. Li, T. Bell, Corrosion Science 461527 (2004).

4. J. Baranowska, S.E. Franklin, Wear 264899 (2008).

5. L. Nosei, S. Farina, M. Ávalos, L. Náchez, B.J. Gómez and J. Feugeas, Thin Solid Films 5161044 (2008).

6. I. Lee, Current Applied Physics 9 S257 (2009).

7. H.R. Abedi, M. Salehi, M. Yazdkhasti, A. Hemmasian-E, Vacuum 85443 (2010).

8. P. Corengia, G. Ybarra, C. Moina, A. Cabo and E. Broitman, Surface \& Coatings Technology 18763 (2004).

9. X. Y. Li and H. Dong, Materials Science and Technology 191427 (2003).

10. C. Issartel., H. Buscail., E. Caudron., R. Cueff., F. Riffard., S. Perrier., P. Jacquet and M. Lambertin. Materials Science Forum 595-598 987 (2008).

11. N. Mingolo, A.P. Tschiptschin, C.E. Pinedo. Surface \& Coatings Technology 2014215 (2006).

12. R. L. O. Basso, V. L. Pimentel, S. Weber, G. Marcos, T. Czerwiec. Journal of Applied Physics 105124914 (2009).

13. Y. Sun, X.Y. Li and T. Bell, Journal of Materials Science 344793 (1999).

14. E. Menthe and K.-T. Rie, Surface \& Coatings Technology 116-119 199 (1999).

15. H. Asteman, J.-E. Svensson, L.-G. Johansson and M. Norell, Oxidation of Metals, 5295 (1999) 
16. H. Asteman, J.-E. Svensson, M. Norell and L.-G. Johansson, Oxidation of Metals, 5411 (2000)

17. J. Oddershede, T.L. Christiansen, K. Ståhl and M.A.J. Somers, Scripta Materialia 62290 (2010).

18. S. Parascandola, W. Möller and D.L. Williamson, Applied Physics Letters, 762194 (2000).

19. X. Xu, L. Wang, Z. Yu, , J. Qiang, Z. Hei, Metallurgical and Materials Transactions, 31A, 1193 (2000).

20. M. Tsujikawa, S. Noguchi, N. Yamauchi, N. Ueda and T. Sone, Surface \& Coatings Technology 2015102 (2007).

21. S.D. de Souza, M. Olzon-Dionysio, E.J. Miola, C.O. Paiva-Santos, Surface and Coatings Technology 184 176 (2004). 